\title{
Sulfometuron Incorporation in Cationic Micelles Adsorbed on Montmorillonite
}

\author{
Yael Golda Mishael, ${ }^{\dagger}$ Tomas Undabeytia, ${ }^{\ddagger}$ Giora Rytwo,$\S$ \\ BrigitTe Papahadjopoulos-Sternberg, $"$ Baruch Rubin, ${ }^{\perp}$ AND Shlomo NiR $*$, \\ Seagram Center for Soil and Water Sciences and Department of Field Crops, Vegetables and Genetics, \\ Faculty of Agricultural, Food and Environmental Sciences, Hebrew University of Jerusalem, \\ Rehovot 76100, Israel, Instituto de Recursos Naturales y Agrobiologia, CSIC, Sevilla, Spain, \\ Tel Hai Academic College, Upper Galilee, Israel, and Nano Analytical Laboratory, \\ San Francisco, California 94118
}

\begin{abstract}
The aim of this study was to understand the interactions between alkylammonium cations present as monomers and micelles and a clay mineral, montmorillonite, to develop slow release formulations of anionic herbicides, such as sulfometuron (SFM) whose leaching in soils is an environmental and economic problem. In the proposed formulation the herbicide is incorporated in positively charged micelles of quaternary amine cations, which in turn adsorb on the negatively charged clay. The adsorption of hexadecyltrimethylammonium (HDTMA) and octadecyltrimethylammonium (ODTMA) on montmorillonite was studied above and below their critical micelle concentrations (CMC). At concentrations above the CMC, the loading exceeded the clay's cation exchange capacity (CEC) and indicated higher affinity of the cation with the longer alkyl chain. An adsorption model could adequately simulate adsorption at concentrations below the $\mathrm{CMC}$, and yield fair predictions for the effect of ionic strength. The model indicated that above the CMC adsorbed micelles contributed significantly to the amount of ODTMA adsorbed. Evidence for adsorption of ODTMA micelles on montmorillonite was provided by X-ray diffraction, freeze-fracture electron microscopy, and dialysis bag measurements. SFM was not adsorbed directly on the clay mineral, and adsorbed at low levels, when the organic cation was adsorbed as monomers. In contrast, a large fraction of SFM adsorbed on the clay mineral when incorporated in micelles that adsorbed on the clay.
\end{abstract}

KEYWORDS: Hexadecyltrimethylammonium; octadecyltrimethylammonium; micelles; montmorillonite; sulfometuron; adsorption model; freeze-fracture electron microscopy; X-ray diffraction

\section{INTRODUCTION}

Surfactants such as alkylammonium cations can modify interface properties and form organized structures including micelles. The adsorption of alkylammonium cations on clay minerals has been widely studied (1-4). Alkylammonium cations adsorbed on several clay minerals up to the cation exchange capacity (CEC) by cation exchange, and adsorbed above the CEC by van der Waals forces through interactions among the alkyl chains of the cations, and between the alkyl chains and clay surface sites $(5,6)$.

The affinity of organic cations to the clay has been described by an adsorption model, which considers two complexes: a neutral complex between a cation and a clay mineral site, and

* Corresponding author. Phone: 972-8-9489172. Fax: 972-8-9475181. E-mail: NIR1@agri.huji.ac.il.

† Seagram Center for Soil and Water Sciences, Hebrew University of Jerusalem.

Instituto de Recursos Naturales y Agrobiologia.

$\S$ Tel Hai Academic College.

"Nano Analytical Laboratory.

${ }^{\perp}$ Department of Field Crops, Vegetables and Genetics, Hebrew University of Jerusalem. a positively charged complex of the cation with the neutral complex. For certain monovalent organic dyes the binding coefficients describing the complexations are several orders of magnitude higher than those of inorganic cations $(7,8)$. The model predicted an increase in cation adsorption for monovalent organic dyes as a result of an increase in the ionic strength, at adsorbed amounts higher than the CEC. For quaternary amine cations the model predicted a decrease in the adsorption (9).

Recent studies using atomic force microscopy focused on the structures formed by alkylammonium cations on a clay surface, above and below their critical micelle concentrations (CMC). The studies have indicated the presence of several different structures of surface aggregates including, under specific conditions, micelles (10-13).

Adsorption of organic cations on clay minerals, such as montmorillonite, at loadings up to the CEC, can result in modification of their surfaces from hydrophilic to hydrophobic. The hydrophobic organo-clay can be used as a sorbent of organic pollutants and as a basis for a formulation of hydrophobic herbicides, which can reduce their leaching in soil, as well as their surface migration $(2,14-18)$. 
<smiles>CCCCCCC</smiles>

HDTMA<smiles>CCCCCC</smiles>

ODTMA

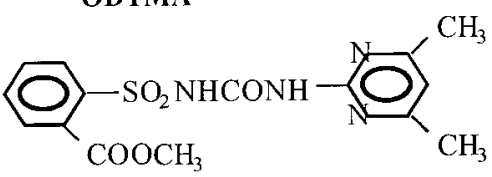

Sulfometuron

Figure 1. Structural formulas of the molecules used.

The current work presents a new approach for the preparation of formulations of anionic herbicides, such as sulfometuron (SFM), which is a weak acid whose solubility in water increases at high $\mathrm{pH}$. Consequently, leaching of the herbicide to deep soil layers poses a severe problem (19-21). Our approach is based on incorporating SFM in the positively charged micelles of quaternary amine cations, which can adsorb on a negatively charged clay mineral, such as montmorillonite. SFM does not adsorb directly on the clay mineral.

As a first step in the design of such formulations, we present a study on the interactions between alkylammonium cations and montmorillonite. In this work the adsorption on montmorillonite of hexadecyltrimethylammonium (HDTMA) and octadecyltrimethylammonium (ODTMA) above and below their CMC, i.e., $1 \mathrm{mM}$ and $0.3 \mathrm{mM}$, respectively, was studied at different ionic strengths and modeled. SFM was incorporated in these quaternary amine cation micelles, which were later adsorbed on a clay mineral.

Our study also includes X-ray diffraction measurements and freeze-fracture electron microscopy. A critical point was to explore transformations of micelles to monomers in the presence of the clay mineral surface, which can result in reduced adsorption of the anionic herbicide on the clay-lipid complexes.

\section{MATERIALS AND METHODS}

Materials. The clay used was Wyoming Na-montmorillonite (SWy2) obtained from the Source Clays Repository of The Clay Minerals Society (Columbia, MO). Its CEC is $0.8 \mathrm{mmol} / \mathrm{g}$ (8). HDTMA, ODTMA, $\mathrm{NaCl}$, and $\mathrm{CsCl}$ were purchased from Sigma-Aldrich (Sigma Chemical Co., St. Louis, MO). Sodiumtetraborate-10-hydrat was obtained from Riedel-de Haen (Seeize, Germany). HPLC acetonitrile and HPLC water were purchased from Merck (Darmstadt, Germany). Sulfometuron 2-[3-4,6-dimethylpyrimidin-2-yl ureidosulfonylbenzoic acid (analytical grade), $\mathrm{p} K_{\mathrm{a}}=5.2$, was obtained from E. I. Du Pont de Nemours \& Company (Wilmington, DE). Dialysis bags made of regenerated cellulose 1000D were obtained from Bio Lab LTD (Jerusalem, Israel). The structural formulas of the herbicide and the organic cations are shown in Figure 1.

Methods. Adsorption of the Organic Cations on Montmorillonite at Different Ionic Strengths. The adsorption of HDTMA and ODTMA was measured at added concentrations of $0-10 \mathrm{mM}$ by using polycarbonate centrifuge tubes. For concentrations above the CMC, 5 $\mathrm{mL}$ of a $0.5 \%$ clay suspension (final $1.7 \mathrm{~g} / \mathrm{L}$ ) was added to $10 \mathrm{~mL}$ of the organic cation solutions. At added concentrations below the CMC, $60 \mathrm{~mL}$ of a $0.033 \%$ (final $0.11 \mathrm{~g} / \mathrm{L}$ ) or $0.009 \%$ (final $0.03 \mathrm{~g} / \mathrm{L}$ ) clay suspension was added to $120 \mathrm{~mL}$ of the cation solutions. Adsorption of ODTMA was also measured in the presence of 100 and $500 \mathrm{mM}$ $\mathrm{NaCl}$ or $\mathrm{CsCl}$. The suspensions were kept under continuous agitation, using a shaker, for $3 \mathrm{~d}$ to reach equilibration.

The pHs of the HDTMA and ODTMA solutions ranged between 5 and 6.4, depending on the cation concentration. The $\mathrm{pH}$ increased to 7.2-7.9 after adding the clay suspension, because of the high $\mathrm{pH}(7.9)$ of the clay.

The adsorption of ODTMA on the clay was also carried out by using dialysis bags containing $20 \mathrm{~mL}$ of an ODTMA solution inserted into a centrifuge tube containing $40 \mathrm{~mL}$ of water reaching the same final concentrations of ODTMA as in the adsorption experiment with tubes. The dialysis bags have a limit of $1000 \mathrm{D}$ on the size of the molecules/ particles that can permeate through them; i.e., the micelles cannot pass through. The clay was added inside or outside the dialysis bag. The suspensions were kept under continuous agitation for $3 \mathrm{~d}$ to reach equilibration.

Supernatants were separated by centrifugation at $15000-20000 \mathrm{~g}$ for $30 \mathrm{~min}$. The precipitates were freeze-dried. The percent of carbon in the precipitates, indicating the amount of cation adsorbed, was measured using a CHNSO analyzer, Carlo-Erba 1108.

Freeze-Fracture Electron Microscopy. For freeze-fracture electron microscopy the samples, ODTMA, montmorillonite, and ODTMA adsorbed on montmorillonite, were quenched using sandwich technique and liquid-nitrogen-cooled propane. Applying this technique, shock freezing of the samples was performed at a cooling rate of about 10,000 degrees per second suppressing any ice-crystal-related artifact formation (22). The exposed fracture planes were shadowed with platinum for $30 \mathrm{~s}$ at an angle of 25-35 degrees, and with carbon for $35 \mathrm{~s}(2 \mathrm{kV} /$ $60-70 \mathrm{~mA}, 1 \times 10^{-5}$ Torr) using a freeze-etching device JEOL JFD9000. The replicas produced by this technique were cleaned with concentrated fuming $\mathrm{HNO}_{3}$ for 24 to $36 \mathrm{~h}$ and examined with a transmission electron microscope JEOL 100S.

$X$-ray Diffraction. The basal X-ray diffraction spacings of ODTMA $(6 \mathrm{mM})$ and ODTMA-clay were measured in the same range of concentrations as in the adsorption measurements. On glass microscope slides, $1.5-2 \mathrm{~mL}$ of the ODTMA solution, or of the clay-ODTMA suspension, were placed, and left to sediment as an oriented sample for $3 \mathrm{~d}$. The basal spacing was measured using an X-ray diffractometer (Philips 1030, Philips Scientific and Analytical Equipment, Eindhoven, The Netherlands) with Co $\mathrm{K} \alpha$ radiation $(\lambda=1.7889 \AA)$.

Model Calculations. Model calculations followed the procedure described earlier $(7,8)$. The three main elements of this model are as follows. (1) Consideration of specific binding to the surface. The total amounts of cations adsorbed are composed of cations bound (Stern layer) and those residing in the electrical double layer. (2) The electrostatic Gouy-Chapman equations are solved for a suspension containing cations and anions of various valencies; changes in the surface charge density due to complexation are explicitly considered. (3) The amount of sites in the sorbent is considered, which results in a decrease in the concentration of the cations in solution, in a closed system.

The binding coefficients of the inorganic cations in the system were taken from previous studies $(23,24)$. The intrinsic binding coefficients $K$ and $\bar{K}$ which reflect the strength of the binding are considered to be parameters that can be determined from adsorption data. The first coefficient, $K$, defines the formation of a neutral complex between a cation and a site on the clay mineral surface and $\bar{K}$ defines a positively charged complex of the cation with a neutral one. To compare experimental data and calculated values, statistical criteria used were $R^{2}$ and the root-mean-square error (RMSE).

SFM Incorporation in Micelles. All solutions of SFM were prepared in a buffer solution ( $\mathrm{pH} 8.5$ ) of $70 \% 0.05 \mathrm{M}$ sodium tetraborate-10hydrate and $30 \% 0.1 \mathrm{M} \mathrm{HCl}$. Dialysis bags containing $20 \mathrm{~mL}$ of SFM and ODTMA were added to $40 \mathrm{~mL}$ of the buffer solution in centrifuge tubes (Table 4). The tubes were kept under continuous agitation for $3 \mathrm{~d}$, reaching equilibration. SFM concentrations were measured inside and outside the dialysis bag to determine the percent of SFM bound to micelles and in solution.

For SFM analysis, all supernatants were filtered with Teflon filters (Pall Corp., Ann Arbor, MI) of $0.2-\mu \mathrm{m}$ pore diameter. SFM was analyzed by HPLC (Merck Hitachi 6200, Tokyo, Japan) equipped with 

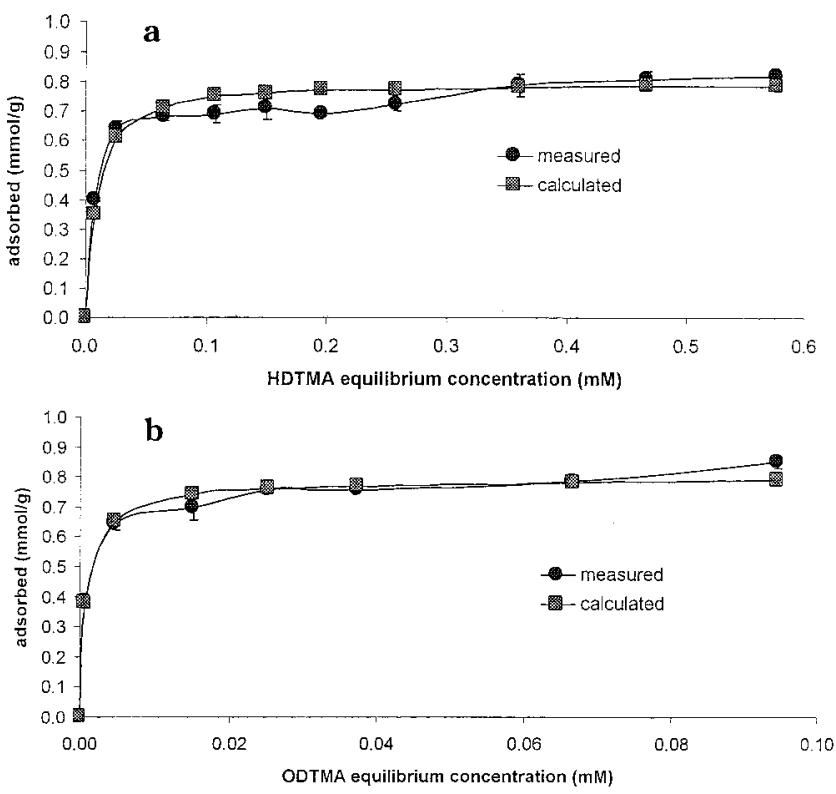

Figure 2. Adsorption isotherms of (a) HDTMA on montmorillonite $(0.11$ $\mathrm{g} / \mathrm{L})$ and (b) ODTMA on montmorillonite $(0.03 \mathrm{~g} / \mathrm{L})$.

PDA detector set at a wavelength of $232 \mathrm{~nm}$. The reverse-phase column was LiChrospher 100 RP-18 (5 mM) (Merck, Darmstadt, Germany). The mobile phase was $70 \%$ acetonitrile and 30\% acidified water (trifluoroacetic acid). The flow rate was $1.0 \mathrm{~mL} \mathrm{~min}^{-1}$. The retention time was $2.7 \mathrm{~min}$. The presence of the cations did not cause any interference with SFM detection.

SFM Speciation and Adsorption on Clay with Micelles. All solutions of SFM were prepared in the buffer solution ( $\mathrm{pH}$ 8.5). Dialysis bags containing $20 \mathrm{~mL}$ of SFM and HDTMA or ODTMA were added to 40 $\mathrm{mL}$ of the buffer solution in centrifuge tubes (Tables 5 and $\mathbf{6}$ ). The tubes were kept under continuous agitation for 3 days, reaching equilibration. To measure SFM adsorption on the clay mineral in the presence of micelles, the clay mineral was added inside the dialysis bags. To measure SFM adsorption on clay without micelles, the clay mineral was added outside the dialysis bags. In both cases SFM concentrations were measured (after filtering the samples) inside and outside the dialysis bag to determine the percent of SFM bound to micelles, adsorbed on clay, and in solution. The concentration of SFM measured outside the dialysis bag is of SFM in solution, while the concentration measured inside the bag is of SFM bound to micelles and of SFM in solution. Because of chemical equilibrium, the concentration of SFM in solution inside and outside the dialysis bag will be the same. The concentration of SFM adsorbed on the clay is deduced by knowing the total amount of SFM added to the system.

\section{RESULTS AND DISCUSSION}

Adsorption of ODTMA and HDTMA on Montmorillonite. Adsorption Below the CMC. The adsorption of ODTMA and HDTMA at concentrations below their CMC is presented in Figure 2a,b. To work at molar concentrations below the CMC and maintain the same range of ratios between the organic cation and clay as used at concentrations above the CMC, the clay concentrations used were very low: $0.03 \mathrm{~g} / \mathrm{L}$ for ODTMA adsorption and $0.11 \mathrm{~g} / \mathrm{L}$ for HDTMA adsorption. At these concentrations of organic cations (Figure $\mathbf{2 a}, \mathbf{b}$ ), there are only monomers in the system, i.e., only monomers can adsorb. In both cases the saturation levels are slightly above the CEC although the clay concentration in ODTMA adsorption was 3 -fold less, indicating higher affinity of ODTMA to the clay than that of HDTMA.

Model Calculations. The binding coefficients were determined for concentrations below the CMC as described in ref 8 . Calculated values of HDTMA and ODTMA adsorbed are in
Table 1. Binding Coefficients of HDTMA and ODTMA

\begin{tabular}{ccccc}
\hline cation & $K\left(\mathrm{M}^{-1}\right)$ & $\bar{K}\left(\mathrm{M}^{-1}\right)$ & $R^{2}$ & $\mathrm{RMSE}(\mathrm{mmol} / \mathrm{g})$ \\
\hline HDTMA & 2000 & 50 & 0.98 & 0.05 \\
ODTMA & 8000 & 200 & 0.99 & 0.04 \\
\hline
\end{tabular}

Table 2. Effect of $\mathrm{Na}^{+}, \mathrm{Cs}^{+}$, and lonic Strength on ODTMA Adsorption on Montmorillonite (ODTMA Was Added at Concentrations below the $\mathrm{CMC}$, to $0.03 \mathrm{~g} / \mathrm{L}$ Clay)

\begin{tabular}{|c|c|c|c|c|}
\hline & & ODTMA added & $\begin{array}{r}\text { ODTM } \\
(\mathrm{m}\end{array}$ & $\begin{array}{l}\text { orbed } \\
\text { g) }\end{array}$ \\
\hline salt & $n M)$ & $(\mathrm{mM})$ & measured $^{a}$ & $\overline{\text { calculated }}$ \\
\hline $\mathrm{NaCl}$ & & 0.024 & 0.64 & 0.65 \\
\hline & 100 & & 0.32 & 0.27 \\
\hline & 500 & & 0.14 & 0.13 \\
\hline & & 0.048 & 0.76 & 0.76 \\
\hline & 100 & & 0.35 & 0.40 \\
\hline & 500 & & 0.29 & 0.21 \\
\hline & & 0.12 & 0.85 & 0.79 \\
\hline & 100 & & 0.60 & 0.56 \\
\hline & 500 & & 0.33 & 0.39 \\
\hline $\mathrm{CsCl}$ & 100 & 0.024 & 0.09 & 0.07 \\
\hline & 500 & & 0.01 & 0.02 \\
\hline & 100 & 0.048 & 0.04 & 0.04 \\
\hline & 500 & & 0.02 & 0.01 \\
\hline
\end{tabular}

${ }^{a}$ The standard deviations obtained for ODTMA adsorption range between 0.0 and $0.07 \mathrm{mmol} / \mathrm{g}$. The method of detection can introduce $10 \%$ error.

good agreement with the experimental data (Figure 2a and b and Table 1), with $R^{2}$ values of 0.98 and 0.99 , respectively. The binding coefficients used are given in Table 1. Values of RMSE fall within the experimental error range. Model calculations were also applied using different ionic strengths (see below). The higher binding coefficients of ODTMA in comparison to those of HDTMA illustrate its higher affinity to the clay.

Effect of Ionic Strength on Monomer Adsorption. The adsorption of ODTMA below the CMC was also measured at different ionic strengths: $100 \mathrm{mM}$ and $500 \mathrm{mM}$ of $\mathrm{NaCl}$ or $\mathrm{CsCl}$ (Table 2). ODTMA adsorption decreased with the increase in the ionic strength. The calculated values of ODTMA adsorption at different ionic strengths are in good agreement with the experimental data. A decrease in cation adsorption with an increase in the ionic strength was also found in the cases of benzyltrimethylammonium (BTMA), benzyltriethylammonium (BTEA) (9, 25), and HDTMA adsorption (3). The level of reduction in ODTMA adsorption was dependent on the inorganic cation in competition. $\mathrm{Cs}^{+}$had a stronger effect on the decrease in the amounts of ODTMA adsorbed than $\mathrm{Na}^{+}$, which correlates with the higher binding coefficient of $\mathrm{Cs}^{+}(23)$. The adsorption of monovalent organic dyes to montmorillonite and pillared clay at amounts exceeding the CEC increased as the ionic strength increased $(7,8,25)$. The explanation was that the increased ionic strength reduced the positive surface potential of the clay and enabled higher cation adsorption. A decrease in ODTMA adsorption at high ionic strength is due to the significantly smaller binding coefficients of ODTMA (Table 1) than those of the dyes, as was also found for BTMA and BTEA (9).

Adsorption Above the CMC. The adsorption isotherms of HDTMA and ODTMA, at added concentrations above the CMC, are presented in Figure 3. At amounts added less than the CEC $(0.8 \mathrm{mmol} / \mathrm{g})$, essentially all the cation was adsorbed, indicating a very large affinity of the cations to the clay mineral. The maximal adsorption levels reached are above the CEC in both cases ( 1 mmol HDTMA/g clay (125\% of the CEC) and 


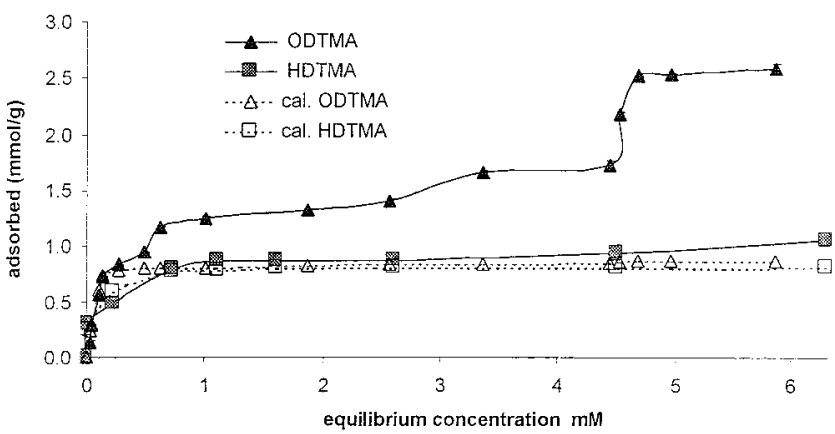

Figure 3. Adsorption isotherms of HDTMA and ODTMA on montmorillonite $(1.6 \mathrm{~g} / \mathrm{L})$.

Table 3. ODTMA Adsorption on Clay Added Inside or outside Dialysis Bags

\begin{tabular}{lcc}
\hline & ODTMA added $(\mathrm{mM})$ & ODTMA adsorbed $(\mathrm{mmol} / \mathrm{g})^{\mathrm{a}}$ \\
\hline & Clay Concentration $=0.03 \mathrm{~g} / \mathrm{L}($ below CMC) \\
in & 0.024 & 0.70 \\
out & & 0.70 \\
in & 0.048 & 0.81 \\
out & & 0.75 \\
in & 0.1 & 0.81 \\
out & & 0.77 \\
& Clay Concentration $=1.6 \mathrm{~g} / \mathrm{L}$ (above CMC) \\
in & 2 & 0.99 \\
out & & 0.95 \\
in & 4 & 1.22 \\
out & & 1.13 \\
in & 5 & 1.12 \\
out & & 1.05 \\
in & 6 & 1.81 \\
out & & 1.63
\end{tabular}

${ }^{a}$ The standard deviations obtained for ODTMA adsorption range between 0.0 and $0.1 \mathrm{mmol} / \mathrm{g}$. The method of detection can introduce $10 \%$ error.

$2.56 \mathrm{mmol}$ ODTMA/g clay (320\% of the CEC)), indicating higher affinity of ODTMA to the clay. Higher adsorption is expected with an increase in the alkylammonium chain due to larger van der Waals interactions between chains (5). Clearly, the longer alkyl chain of ODTMA, which reduces its CMC, also affects its equilibrium distribution in the suspension toward formation of neutral and charged complexes with the clay mineral sites.

Applying the binding coefficients (Table 1) at concentrations above the CMC emphasized the large contribution of micelles to the adsorption of ODTMA. The differences between the calculated values and measured ones give an indication of the contribution of micelles (Figure 3). This phenomenon is more pronounced in the case of ODTMA adsorption because of its high affinity to the clay and its low CMC.

Adsorption of Monomers and Micelles Using Dialysis Bags. Another approach to test micelle versus monomer adsorption was also used. The adsorption of ODTMA added at concentrations above and below the CMC, on montmorillonite, was measured by adding the clay inside or outside the dialysis bag. ODTMA solution was added inside the dialysis bags (in both cases), i.e., the micelles were only present inside the dialysis bag.

At ODTMA concentrations below the CMC, the same amount adsorbed on the clay was expected to be found whether the clay was inside or outside the dialysis bag, as there are only monomers in the system, which can pass through the bag. As shown in Table 3 the amounts of ODTMA adsorbed, when added at concentrations below the CMC, were similar, when the clay was inside or outside dialysis bags.
Table 4. Percent of SFM Bound to Micelles

\begin{tabular}{ccc}
\hline ODTMA (mM) & SFM (mM) & $\begin{array}{c}\text { SFM bound } \\
\text { to micelles }(\%)^{a}\end{array}$ \\
\hline 0.1 & 0.01 & 0 \\
2.5 & 0.125 & 76.1 \\
2.5 & 0.25 & 73.0 \\
4 & 0.25 & 82.2 \\
5 & 0.25 & 81.1 \\
5 & 0.5 & 82.5 \\
5 & 1.25 & 72.4 \\
5 & 2.5 & 56.4 \\
6 & 0.25 & 86.5 \\
8 & 0.25 & 85.0 \\
15 & 0.75 & 89.3 \\
\hline
\end{tabular}
$4.9 \%$

${ }^{a}$ The standard deviations obtained for SFM speciation range between 0.7 and

Also, at concentrations added above the $\mathrm{CMC}$ the adsorption level in both cases was similar, just $4-11 \%$ more when the clay was inside the bag (Table 3 ). We suggest that at added concentrations above the $\mathrm{CMC}$, due to monomer adsorption outside the dialysis bag, monomers from inside the bag will pass through it in order to reach equilibrium and micelles will decompose into monomers and so on. At equilibrium (after 3 days) the levels of ODTMA adsorption on the clay, when added inside or outside the dialysis bag, were similar. However, the adsorption when the clay is added outside should be as monomers; and when added inside should be as monomers and micelles, as in the case of adsorption in tubes. The adsorption of ODTMA as micelles was further demonstrated by adsorption of ODTMA with SFM on the clay mineral and by X-ray diffraction and freeze-fracture measurements (see below).

SFM Incorporation in Micelles. To evaluate the affinity of the negatively charged herbicide to the positively charged micelles, the herbicide and cation were placed in dialysis bags at different concentrations. By measuring the concentration of SFM inside and outside the bags, the percent of SFM bound to micelles was determined (Table 4).

As expected, at concentrations below the CMC, e.g., $0.1 \mathrm{mM}$ ODTMA, no reduction in the solution concentration of SFM was observed. At added concentrations above the CMC, 2.515 mM ODTMA, $76.1-89.3 \%$ of the added SFM bound to the micelles.

When adding $5 \mathrm{mM}$ ODTMA with increasing concentrations of SFM $(0.25-2.5 \mathrm{mM})$ there was a decrease in the percent of SFM bound to micelles. The percent of SFM bound to micelles increases as the ratio between the two increases, as can also be seen when adding $0.25 \mathrm{mM}$ SFM with increasing concentrations of ODTMA (2.5-8 mM). Increasing the micelle concentration enables more herbicide molecules to bind.

The adsorption of neutral molecules on colloidal particles, e.g., clay minerals, can be described by the Scatchard equation, which is equivalent to the Langmuir equation $(26,27)$. We used this model to evaluate the affinity of the herbicide to the micelles, assuming each ODTMA molecule can mostly bind one herbicide molecule. The binding coefficient $k\left(\mathrm{M}^{-1}\right)$ is a rough measure of the affinity of the herbicide to the micelles. The applicability of the Scatchard equation was tested by its ability to adequately simulate the binding results. The results indicated that the Scatchard equation can yield good simulation to the experimental percents of SFM bound $\left(R^{2}=0.98\right.$ and RMSE $\left.=1.3 \times 10^{-5} \mathrm{M}\right)$. The values of binding coefficients provide a convenient scale for comparison, rather than absolute values of the changes of the free adsorption energy (27). The applicability of the Scatchard (or Langmuir) equation for 
Table 5. SFM Speciation and Adsorption at Different Clay Concentrations Added Inside and Outside of Dialysis Bags in the Presence of ODTMA

\begin{tabular}{|c|c|c|c|c|c|c|}
\hline \multicolumn{2}{|c|}{ clay added (g/L) } & \multirow{2}{*}{$\begin{array}{c}\begin{array}{c}\text { ODTMA added } \\
(\mathrm{mM})\end{array} \\
15\end{array}$} & \multirow{2}{*}{$\begin{array}{c}\begin{array}{c}\text { SFM added } \\
(\mathrm{mM})\end{array} \\
0.75\end{array}$} & \multirow[t]{2}{*}{$\begin{array}{l}\text { SFM adsorbed } \\
\text { on clay }(\%)^{a}\end{array}$} & \multirow{2}{*}{$\begin{array}{c}\begin{array}{c}\text { SFM bound to } \\
\text { micelles in solution }(\%)^{a}\end{array} \\
89.3\end{array}$} & \multirow{2}{*}{$\frac{\text { SFM in solution }(\%)^{a}}{10.7}$} \\
\hline 0 & in & & & & & \\
\hline 1 & in & 15 & 0.75 & 5.8 & 84.9 & 9.3 \\
\hline 1.6 & in & 15 & 0.75 & 11.1 & 78.6 & 10.3 \\
\hline 3.5 & in & 15 & 0.75 & 47.8 & 37.1 & 15.0 \\
\hline 5 & in & 15 & 0.75 & 85.5 & 6.6 & 7.9 \\
\hline 0 & in & 2.5 & 0.25 & & 76.6 & 23.4 \\
\hline 1 & in & 2.5 & 0.25 & 22.5 & 58.3 & 19.0 \\
\hline 1.6 & in & 2.5 & 0.25 & 65.8 & 12.2 & 21.9 \\
\hline 2.5 & in & 2.5 & 0.25 & 80.3 & 1.0 & 19.5 \\
\hline 3.5 & in & 2.5 & 0.25 & 63.8 & 0.4 & 35.8 \\
\hline 5 & in & 2.5 & 0.25 & 41.1 & 0.2 & 58.5 \\
\hline 1.6 & out & 2.5 & 0.25 & 1.6 & 82.6 & 15.8 \\
\hline 3.5 & out & 2.5 & 0.25 & 3.5 & 82.8 & 13.8 \\
\hline
\end{tabular}

${ }^{a}$ The standard deviations obtained for SFM speciation range between 0.8 and $3 \%$.

Table 6. SFM Speciation and Adsorption at Different Clay Concentrations in the Presence of HDTMA

\begin{tabular}{|c|c|c|c|c|c|}
\hline $\begin{array}{l}\text { clay added } \\
(\mathrm{g} / \mathrm{L})\end{array}$ & $\begin{array}{l}\text { HDTMA added } \\
\qquad(\mathrm{mM})\end{array}$ & $\begin{array}{l}\text { SFM added } \\
\text { (mM) }\end{array}$ & $\begin{array}{l}\text { SFM adsorbed on clay } \\
\qquad(\%)^{a}\end{array}$ & $\begin{array}{l}\text { SFM bound to micelles } \\
\text { in solution }(\%)^{a}\end{array}$ & $\begin{array}{l}\text { SFM in solution } \\
(\%)^{a}\end{array}$ \\
\hline 0 & 15 & 0.75 & & 85.0 & 15.0 \\
\hline 1 & 15 & 0.75 & 11.3 & 81.0 & 7.9 \\
\hline 1.6 & 15 & 0.75 & 19.4 & 73.3 & 7.2 \\
\hline 3.5 & 15 & 0.75 & 44.3 & 50.0 & 6.1 \\
\hline 5 & 15 & 0.75 & 60.6 & 32.4 & 6.9 \\
\hline
\end{tabular}

a The standard deviations obtained for SFM speciation range between 0.5 and $8 \%$.

describing binding of the anionic SFM to the positively charged ODTMA micelles is due to the fact that the molar ratio between SFM and ODTMA was small: 0.03 to 0.1 . Consequently, the degree of charge neutralization of the micelles due to SFM binding was not significant. The binding coefficient calculated $\left(500 \mathrm{M}^{-1}\right)$ does not imply high affinity of SFM to the micelles, but the fraction of SFM adsorbed on the clay mineral through its binding to the micelles was high (see below).

SFM Speciation and Adsorption on Montmorillonite in the Presence of Micelles. The organic cations and the anionic SFM were added inside dialysis bags. The concentration of SFM inside and outside the dialysis bags was measured, which gave the percent of SFM bound to micelles, adsorbed on the clay mineral, and in solution (Table 5).

SFM alone did not adsorb on montmorillonite. When adding montmorillonite inside a dialysis bag at increasing concentrations $(0-5 \mathrm{~g} / \mathrm{L})(15 \mathrm{mM}$ ODTMA and $0.75 \mathrm{mM}$ SFM), the percent of SFM adsorbed on the clay increased, whereas the percent of SFM bound to micelles in solution decreased and the fraction of SFM in solution remained constant (Table 5). The same trend was found with HDTMA added at the same concentrations (Table 6). This outcome indicates that essentially only SFM bound to micelles adsorbs on the clay.

When adding $2.5 \mathrm{mM}$ ODTMA and $0.25 \mathrm{mM}$ SFM with increasing clay concentrations, we found the same trend of increased adsorption of SFM up to a clay concentration of 2.5 $\mathrm{g} / \mathrm{L}$. However, when reaching higher clay concentrations there was a sharp decrease in the percent of SFM adsorbed and a significant increase in the percent of SFM in solution (Table 5). We suggest that the high clay concentration relative to that of ODTMA promoted monomer adsorption, and because of monomer/micelle equilibrium, micelles decomposed, releasing SFM to the solution, with a consequent reduction in SFM adsorption on the clay.

To further test whether the enhanced adsorption of SFM is due to the adsorption of SFM bound to micelles, the adsorption of SFM on the clay mineral was measured by adding $1.6 \mathrm{~g}$ clay/L inside and outside the dialysis bag. ODTMA (2.5 mM) and SFM $(0.25 \mathrm{mM})$ were added inside the dialysis bags (in both cases), i.e., the micelles were only present inside the dialysis bag (Table 5). When the clay was added outside the bag, only $1.6 \%$ of SFM was adsorbed by the clay mineral and $83 \%$ was bound to micelles, whereas when the clay was added inside the bag, $66 \%$ of SFM was adsorbed by the clay and $12 \%$ was bound to micelles. The percent of SFM in solution was essentially the same (16-22\%). It is clear that when the micelles had access to the clay (clay added inside), a much higher percent of SFM adsorbed on the clay, indicating that SFM bound to ODTMA micelles increases its adsorption by the clay. This outcome is noteworthy, as Table $\mathbf{3}$ shows that the clay mineral was positively charged due to monomer adsorption when it was outside the dialysis bag, but a very small percent of SFM adsorbed. The same trend of high adsorption of SFM when the micelles had access to the clay (clay added inside) was found when carrying out the experiment with $3.5 \mathrm{~g} / \mathrm{L}$ clay (Table 5).

The result reported in the last row of Table $\mathbf{5}$, in which about $80 \%$ SFM was bound to micelles for the clay added outside the dialysis bag $(3.5 \mathrm{~g} / \mathrm{L})$, needs explanation, in view of the fact that when the clay $(3.5 \mathrm{~g} / \mathrm{L})$ was inside the bag, there was little SFM bound to the micelles. We should recall that the volume of the dialysis bag was a third of the total volume. In the latter case we had initially $7.5 \mathrm{mM}$ ODTMA and $10.5 \mathrm{~g} / \mathrm{L}$ clay inside the bag. The adsorbed amount of ODTMA as monomers left a very low concentration of ODTMA remaining as micelles, due to their decomposition into monomers. However, when the clay was outside the bag, its concentration there was $5.25 \mathrm{~g} / \mathrm{L}(3.5 \mathrm{~g} / \mathrm{L}$ total). Hence, a higher concentration of ODTMA remained as micelles enabling high SFM binding, in contrast to little SFM adsorption on the clay.

This was further supported by X-ray diffraction and freezefracture measurements (see below). This experiment, which sheds more light on the micelle-monomer-clay system will 

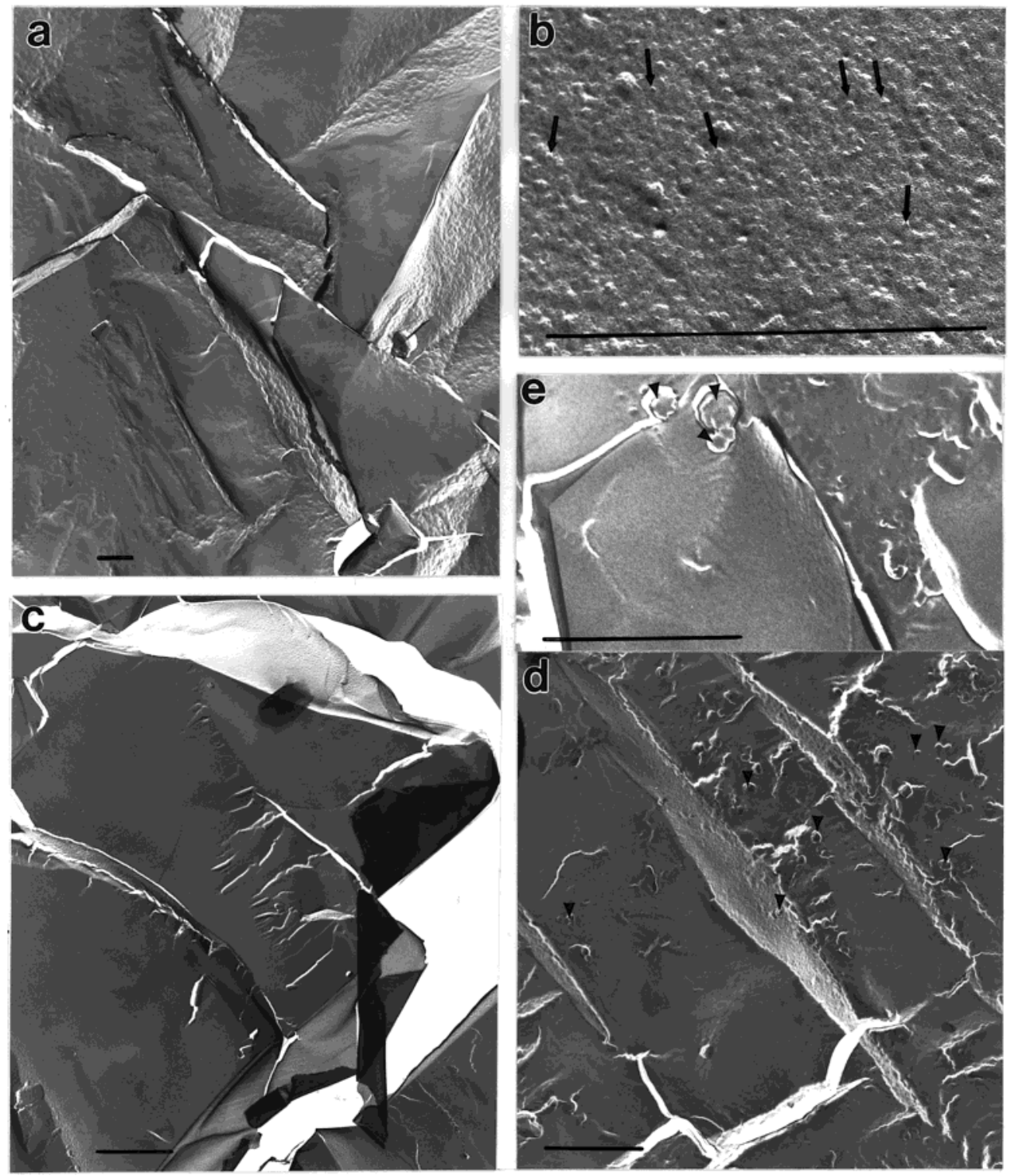

Figure 4. Freeze-fracture electron micrographs of montmorillonite and ODTMA: (a) $1.6 \mathrm{~g}$ montmorillonite/L; (b) ODTMA 6 mM; (c) ODTMA (6 mM) added inside a dialysis bag and the clay suspension $(1.6 \mathrm{~g} / \mathrm{L})$ is outside the bag; $(\mathrm{d}, \mathrm{e})$ unrestrained clay-ODTMA interactions $(6 \mathrm{mM}$ ODTMA + $1.6 \mathrm{~g}$ clay/L, 15-min incubation time; (d) at lower magnification and (e) at higher magnification). On all electron micrographs, the bar represents $1 \mu \mathrm{m}$ and the shadow direction is running from bottom to top.

also enable us to optimize the design of controlled-release formulations based on anionic herbicide incorporated in the micelles adsorbed on the clay mineral. The implication is that to achieve high SFM adsorption it is necessary not to exceed the clay concentration and search for clay and cation concentrations that will give maximum SFM bound to micelles and maximal adsorption of micelles. In fact, a first attempt gave us $94 \%$ of SFM adsorbed by using $5 \mathrm{mM}$ ODTMA, $0.25 \mathrm{mM}$ SFM, and $5 \mathrm{~g} / \mathrm{L}$ clay.

Freeze-Fracture Electron Microscopy. The electron micrographs obtained by freeze-fracture technique display very characteristic features for the clay (Figure 4a) and ODTMA surfactant (Figure 4b) investigated in this study. The clay control sample (Figure 4a, 1.6 g montmorillonite/L) shows welldefined, sharp-edged clods with edge lengths of about 5 to 20 $\mu \mathrm{m}$. The ODTMA control sample (Figure 4b, 6 mM ODTMA) shows a high concentration of micelles in the size range of about 7 to $17 \mathrm{~nm}$. Some of the micelles, visible abundantly in Figure $\mathbf{4 b}$, are marked by arrows.
ODTMA added inside a dialysis bag to a clay suspension outside the dialysis bag (Figure 4c, 6 mM ODTMA $+1.6 \mathrm{~g} / \mathrm{L}$ clay) reveals features of the clay particles remarkably similar to those observed in the control sample (cf. Figure $\mathbf{4 c}$ and $\mathbf{4 a}$ ). Sharp-edged clods in the size range of 2 to $8 \mu \mathrm{m}$ visible in Figure $4 \mathbf{c}$ indicate that ODTMA monomers, which are able to pass dialysis bags, do not alter the clay particle features. As shown in the adsorption experiments, the level of adsorption of ODTMA on the clay mineral added inside or outside the dialysis bag was similar. However, the freeze-fracture measurements confirmed the expected outcome that no micelles would be seen on the clay, because only monomers can pass through the bag and adsorb.

ODTMA micelles, added unrestrained by dialysis bags to clay in suspension (Figure $\mathbf{4 d}$ and $\mathbf{4 e}, 6 \mathrm{mM}$ ODTMA + $1.6 \mathrm{~g}$ clay/ $\mathrm{L}, 15 \mathrm{~min}$ incubation time), lead to large extended areas of sharp-edged clay clods with edge lengths of about 2 to $5 \mu \mathrm{m}$. Micelle aggregates with average diameters of 30 to $160 \mathrm{~nm}$ (sometimes up to $300 \mathrm{~nm}$ ) are adsorbed to clay particles (Figure 


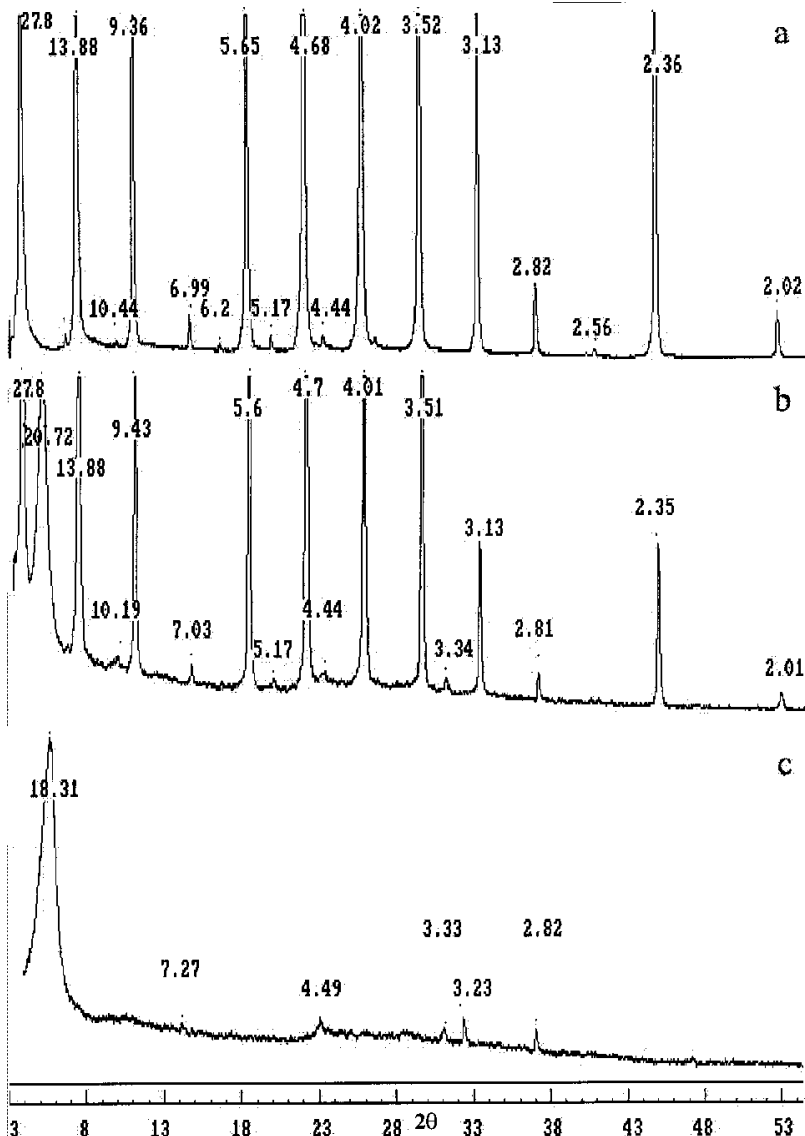

Figure 5. X-ray diffraction of (a) $6 \mathrm{mM}$ ODTMA, (b) $6 \mathrm{mM}$ ODTMA added to $1.6 \mathrm{~g} / \mathrm{L}$ clay added inside a dialysis bag, and (c) $6 \mathrm{mM}$ ODTMA added to $1.6 \mathrm{~g} / \mathrm{L}$ clay added outside a dialysis bag.

4d) as visible in Figure $\mathbf{4 e}$ at higher magnification. Some of the micelle aggregates are marked by arrowheads in Figure $4 \mathbf{d}$ and $\mathbf{4 e}$.

X-ray Diffraction. The basal spacing of the untreated clay was $14.8 \AA$, indicating a bilayer of water molecules present between the silicate layers (28). The diffraction of micelles without clay (6 mM ODTMA) gives a series of very sharp and well-defined peaks, indicating a very organized structure (Figure 5a). All the peaks in this series can be ascribed to different orders of a basal spacing of $27.8 \AA$, according to Bragg's Law: $n \lambda=2 d \sin \theta$, where $\lambda$ is the wavelength of the beam, $d$ is the separation between the reflecting lattice planes, $\theta$ is the glancing angle, and $n$ is the order (29). A basal spacing of $27.8 \AA$ can be ascribed to micelles. The length of two HDTMA molecules is between 31 and $35 \AA$ (12). Considering ODTMA has a longer chain, a spacing of $27.8 \AA$ could represent the presence of somewhat flattened micelles. In Figure $\mathbf{4 b}$ the freeze-fracture measurements demonstrated the presence of micelles. Hence, it is possible that under the conditions in Figure 5a, the dominant structure is also micelles, although on the basis of the X-ray diffraction results alone we cannot rule out an arrangement of several bilayers in which ODTMA molecules are arranged in an oblique orientation.

When adding ODTMA at a low loading, $0.5 \mathrm{mM}$ to $1.6 \mathrm{~g} / \mathrm{L}$ clay (in which case complete adsorption of the cation occurs according to Figure 3), the basal spacing of the clay mineral, $14.2 \AA$, is essentially the same as that without ODTMA.

When adding ODTMA at a higher concentration, $6 \mathrm{mM}$ and $1.6 \mathrm{~g} / \mathrm{L}$ clay inside a dialysis bag (where micelle adsorption was expected), the well-defined series of peaks, due to the micelles (Figure 5a), and an additional peak at $20.7 \AA$ were observed (Figure 5b). We also found the same pattern in the presence of $1.25,1.8$, and $2.65 \mathrm{mM}$ ODTMA (results not shown). It should be noted that most of the peaks appeared and yielded the same spacing when we repeated the measurements using another instrument (Philips), where the $\mathrm{CuK} \alpha$ radiation was $1.54 \AA$.

The peak which corresponds to a basal spacing of $20.7 \AA$ and was not observed in Figure 5a (micelles only) can be attributed to pseudotrimolecular layers of ODTMA between the silicate layers (1). The well-defined peaks, as in Figure 5a, could be due to micelle adsorption on the external surfaces of the clay mineral.

When the clay was added outside the dialysis bag (Figure 5c) and only monomer adsorption was expected, only one strong peak was observed at $18.3 \AA$. Such a spacing might be ascribed to a bilayer of ODTMA monomers lying parallel to the surface of the clay mineral as was found for HDTMA (2). No additional peaks indicating micelle adsorption could be observed. It should be emphasized that the amount of ODTMA adsorbed was similar whether the clay was added inside or outside the dialysis bag. However, in the presence of micelles (clay inside the dialysis bag) the basal spacing was $20.7 \AA$, indicating a difference in the montmorillonite-ODTMA structure.

When adding $5 \mathrm{mM}$ ODTMA to a very concentrated clay suspension (10 g/L), we predicted that the monomers would adsorb, and due to the high clay concentration, micelles would decompose to monomers similar to the adsorption through dialysis bags, and adsorption of ODTMA with SFM at high clay concentrations (Table 5). Indeed, this sample exhibited a basal spacing of only $14.8 \AA$ without any additional peaks. This can indicate monomer adsorption, with fewer layers of organic molecules between clay platelets.

\section{CONCLUDING REMARKS}

The current study presented model calculations for the adsorption of the organic cation ODTMA as monomers on montmorillonite, which suggested that at ODTMA concentration above the $\mathrm{CMC}$, there must be micelle adsorption on the clay mineral. Adsorption of ODTMA micelles on montmorillonite is the basis for the design of formulations of anionic herbicides, such as SFM, for reducing their movement and leaching in soils, which is a serious environmental and economic problem. This design amounts to incorporating the anionic herbicide in micelles of an organic cation of low CMC, such as ODTMA, and subsequently, adsorbing the micelles on the clay mineral. Our results demonstrated that in large excess of ODTMA, the fraction of an anionic herbicide adsorbed increased by increasing the clay concentration. However, in other cases, an increase in clay concentration eventually resulted in micelle disintegration into monomers, due to monomer adsorption on the clay mineral, which depletes the micelles from solution. Hence, an understanding of the adsorption pattern and the ability to predict it is essential for an optimal design of micelle-clay based formulation of anionic herbicides. Micelle adsorption on montmorillonite was observed by freeze-fracture electron microscopy and was also suggested by X-ray diffraction measurements. These measurements exhibited the presence of several well-defined peaks under conditions that ODTMA micelles could adsorb, e.g., when ODTMA and the clay mineral were inside a dialysis bag, whereas only a single peak of the basal spacing (18.3 $\AA$ ) was present when the clay was placed outside the dialysis bag. Under this condition, no adsorbed micelles were observed by freeze-fracture electron microscopy. The biological efficiency 
of the newly designed formulations and their ability to reduce herbicide leaching has been reported (30).

\section{ABBREVIATIONS USED}

SFM, sulfometuron; HDTMA, hexadecyltrimethylammonium; ODTMA, octadecyltrimethylammonium; CMC, critical micelle concentration; CEC, cation exchange capacity.

\section{LITERATURE CITED}

(1) Lagaly, G. Layer charge heterogeneity in vermiculites. Clays Clay Miner. 1982, 30, 215-222.

(2) Jaynes, W. F.; Boyd, S. A. Clay mineral type and organic compound sorption by hexadecyltrimethylammonium-exchanged clays. Soil Sci. Soc. Am. J. 1991, 55, 43-48.

(3) Xu, S.; Boyd, S. A. Cation exchange chemistry of hexadecyltrimethylammonium in a subsoil containing vermiculite. Soil Sci. Soc. Am. J. 1994, 58, 1382-1391.

(4) Xu, S.; Boyd, S. A. Cationic surfactant sorption to a vermiculitic subsoil via hydrophobic bonding. Environ. Sci. Technol. 1995, $29,312-320$.

(5) Theng, B. K. G. The Chemistry of Clay-Organic Reactions; Wiley: New York, 1974.

(6) Zhang, Z.; Sparks, D. L.; Scrivner, N. C. Sorption and desorption of quaternary amine cations on clays. Environ. Sci. Technol. 1993, 27, 1625-1631.

(7) Margulies, L.; Rozen, H.; Nir, S. Model for competitive adsorption of organic cations on clays. Clays Clay Miner. 1988, $36,270-276$

(8) Rytwo, G.; Nir, S.; Margulies, L. Interactions of monovalent organic cations with montmorillonite: adsorption studies and model calculations. Soil Sci. Soc. Am. J. 1995, 59, 554-564.

(9) Polubesova, T.; Rytwo, G.; Nir, S.; Serban, C.; Margulies, L. Adsorption of benzyltrimethylammonium and benzyltriethylammonium on montmorillonite. Clays Clay Miner. 1997, 54, 834-841.

(10) Hayes, W. A.; Schwartz, D. K. Two-stage growth of octadecyltrimethylammonium bromidemonolayers at mica from aqueous solution below the Krafft point. Langmuir 1998, 14, 5913-5917.

(11) Lamont, R. L.; Ducker, W. A. Surface-induced transformations for surfactant aggregates. J. Am. Chem. Soc. 1998, 120, 76027607.

(12) Ducker, W. A.; Wanless, E. J. Adsorption of hexadecyltrimethylammonium bromide to mica: nanometer-scale study of binding site competition effects. Langmuir 1999, 15, 160-168.

(13) Fujii, M.; Li, B.; Fukada, K.; Kato, T.; Seimiya, T. Heterogeneous growth and self-repairing processes of two-dimensional molecular aggregates of adsorbed octadecyltrimethylammonium bromide at cleaved mica/aqueous solution interface as observed by in situ atomic force microscopy. Langmuir 1999, 15, 36893692.

(14) Boyd, S. A.; Lee, J. F.; Mortland, M. M. Attenuating organic contaminant mobility by soil modification. Nature 1988, 333 , 345-347.

(15) El Nahhal, Y.; Nir, S.; Serban, C.; Rabinovitch, O.; Rubin, B. Montmorillonite-phenyltrimethylammonium yields environmentally improved formulations of hydrophobic herbicides. $J$. Agric. Food Chem. 2000, 48, 4791-4801.
(16) Sheng, G.; Wang, X.; Wu, S.; Boyd, S. A. Enhanced sorption of organic contaminants by smectitic soils modified with a cationic surfactant. J. Environ. Qual. 1998, 27, 806-814.

(17) Undabeytia, T.; Nir, S.; Rubin, B. Organo-clay formulations of hydrophobic herbicide norflurazon yield reduced leaching. $J$. Agric. Food Chem. 2000, 48, 4767-4773.

(18) Xu, S.; Sheng, G.; Boyd, S. A. Use of organoclays in pollution abatement. Adv. Agron. 1997, 59, 25-62.

(19) Veeh, R. H.; Inskeep, W. P.; Roe, F. L.; Ferguson, A. H. Transport of chlorsulfuron through soil columns. J. Environ. Qual. 1994, 23, 542-549.

(20) Sarmah, A. K.; Kookana, R. S.; Alston, A. M. Fate and behavior of trisulfusulfuron, metsulfuron-methyl, and chlorsulfuron in Australian soil environment: a review. Aust. J. Agric. Res. 1998, 49, 775-790.

(21) Pool, C. F.; Du-Toit, D. Leaching depth of imazamethabenz methyl and chlorsulfuron and metsulfuron methyl in different soils. Applied Plant Sci. 1995, 9, 43-47.

(22) Sternberg, B. Freeze-fracture electron microscopy of liposomes. In Liposome Technology; Gregoriadis, G., Ed.; CRC Press: Boca Raton, FL, 1993; pp 363-383.

(23) Nir, S.; Hirsch, D.; Navrot, J.; Banin, A. Specific adsorption of lithium, sodium, potassium, cesium, and strontium to montmorillonite: Observations and predictions. Soil Sci. Soc. Am. J. 1986, 50, 40-45.

(24) Rytwo, G.; Banin, A.; Nir, S. Exchange reactions in the $\mathrm{Ca}-$ $\mathrm{Mg}-\mathrm{Na}-$ Montmorillonite system. Clays and Clay Miner. 1996, 44, 276-285.

(25) Mishael, Y. G.; Rytwo, G.; Nir, S.; Crespin, M.; Annabi-Bergaya, F.; Van Damme, H. Interactions of monovalent organic cations with pillared clays. J. Colloid Interface Sci. 1999, 209, 123128.

(26) Nir, S.; Peled, R.; Lee, K. D. Analysis of particle uptake by cells: Binding to several receptors, equilibration time, endocytosis. Colloids Surf. 1994, 89, 45-59.

(27) Nir, S.; Undabeytia, T.; Yaron Marcovich, D.; El Nahhal, Y.; Polubesova, T.; Serban, C.; Rytwo, G.; Lagaly, G.; Rubin, B. Optimization of adsorption of hydrophobic herbicides on montmorillonite preadsorbed by monovalent organic cations: interaction between phenyl rings. Environ. Sci. Technol. 2000, 34, $1269-1274$

(28) MacEwan, D. M. C.; Wilson, M. J. Interlayer and Intercalation Complexes of Clay Minerals; Mineralogical Society: London, 1980.

(29) Atkins, P. W. Physical Chemistry, 5th ed.; Oxford University Press: Oxford, UK, 1994.

(30) Mishael, Y. G.; Undabeytia, T.; Rabinovitz, O.; Rubin, B.; Nir, S. Slow release formulations of sulfometuron incorporated in micelles adsorbed on montmorillonite. J. Agric. Food Chem. 2002, 50, 2864-2869.

Received for review November 13, 2001. Revised manuscript received February 27, 2002. Accepted February 27, 2002. This work was supported in part by The Hebrew University of Jerusalem through a grant from The Wolfson Foundation for Scientific Research, MatchingBergman, a grant 1317 from Israeli Ministry of Science, Culture and Sport, and by Grant G-641-106.8/1999 from G.I.F., the German-Israeli Foundation for Research and Development.

JF011496M 